\title{
Past and Current Dietary Recommendations in the USA: Summation in a Nutshell
}

Jasminka Z. Ilich*and Joy L. Post

Department of Nutrition, Food and Exercise Sciences, Florida State University, USA

*Corresponding author: Jasminka Z. Ilich, Department of Nutrition, Food and Exercise Sciences, Florida State University, USA, Tel: 850-645-7177; Fax: 850-645-5000; E-mail: jilichernst@fsu.edu

Rec date: Aug 13, 2014; Acc date: Oct 09, 2014; Pub date: Oct 17, 2014

Copyright: ( 2014 Ilich JZ, et al. This is an open-access article distributed under the terms of the Creative Commons Attribution License, which permits unrestricted use, distribution, and reproduction in any medium, provided the original author and source are credited.

\section{Abstract}

With the abundance of dietary advice coming from different sources and origins, it is important to identify those coming from the official government or other legitimate non-profit organizations which have been accepted and approved by the USA government. This review gives a brief history of dietary recommendations and their evolvement over time, as well as the description of the current official recommendations in the USA.

Keywords: Food; Dietary recommendations

\section{History of Dietary Recommendations}

The first known official dietary recommendations were issued by British government in 1835 and are known as "British Merchant Seaman's Act". The whole purpose of this Act was to protect health and living conditions of sailors, as well as to ensure enforcement of proposed recommendations, by administering a fine for noncompliance [1] From a nutritional point of view, the Act made $1 / 2$ ounce of either lemon or lime juice+sugar, and a weekly vinegar ration mandatory on ships, in order to prevent scurvy related to vitamin C deficiency. A similar act was signed by President Wilson for the US Federal Government in 1915 [2].

The first food-related records in the USA were published by the Office of The Experiment Station Record, from 1889 to 1946 and comprised 95 volumes, first referred to as the "Agricultural Appropriations Act of 1893". The Office of Experiment Stations administered federal funds that supported research in the disciplines of agriculture and rural life. This Office was also responsible for organizing the research work performed by the US Department of Agriculture (USDA) in agricultural colleges and experiment stations. In this document, researchers described the amounts of calories, fiber, oil, and protein in various plants, as well as certain novel ingredients, such as gluten in wheat [3].

The Experiment Station Record clusters into 2 periods, with the first one known as Atwater Period, superseded by The Bibliography of Agriculture which continues to be published in electronic form and under its own name Agricola; it is a monthly publication compiled in the USDA Library and issued by the U. S. Government Printing Office [4]. All records from The Experiment Station were sent to the University of North Texas Libraries in 2006 and the scanning was completed in 2008.

During World Wars I and II and in-between, there was a renewed interest in dietary standards and the ways to prevent deficiencies in military, or general population. There was also a realization that there was more to nutrition than just energy and protein; e.g. vitamins and minerals. Some of the central, early nutritional scientists who elevated nutrition to the higher levels were Wilbur O. Atwater and Hazel K. Stiebeling, often referred to as the father and mother of nutrition, respectively.

\section{The Father and Mother of Nutrition}

Wilbur O. Atwater (1844-1907) is often called the father of nutrition due to his numerous contributions to the science of nutrition. After earning a doctoral degree in Agricultural Chemistry from Yale he spent most of his working life at Wesleyan University in Connecticut. He created the Atwater System, which was the first indirect calorimetry to measure energy units in food, including in alcohol [5]. Additionally, together with his Wesleyan colleagues, he studied dietary intake of general population; students and families, mostly in Storrs, CT Agricultural Station which later evolved into the University of Connecticut. The reports on dietary intake were published in late 1800s [6].

Hazel K. Stiebeling (1896-1989) has just beginning to be recognized for her pioneering work in vitamin and mineral nutrition and in the development of dietary allowances as we know them today. She received her doctorate in Chemistry from Columbia University and subsequently served as a Head of USDA Bureau of Home Economics. Dr. Stiebeling was instrumental in the publication of first dietary standards and introduction of the term "dietary allowances". Her focus was on studying vitamin $\mathrm{D}$ deposition in bone as well as quantification of dietary standards for vitamins $\mathrm{A}$ and $\mathrm{C}$ and minerals calcium, phosphorus, and iron [7].

\section{Existing Guides Regarding Nutrients and Food}

Dietary Guidelines for Americans are intended for Americans aged 2 years and above, including those at increased risk of chronic disease [8]. They refer to either foods or macronutrients and are not designed to prevent nutritional deficiency, but rather to advise general population about healthy eating. Three primary goals set for Americans by the Guidelines are 1) to balance caloric intake with physical activity in order to manage weight, 2) to consume more foods known to be beneficial to health such as fruits, vegetables, whole grains, fat-free and low-fat dairy products, and seafood, and 3) to reduce consumption of foods that can have negative effects on health 
Page 2 of 3

such as high-sodium foods, trans fats, foods high in cholesterol, foods with added sugars, and refined grains. All details of the Guidelines for 2010 can be found at http://www.health.gov/dietaryguidelines/ dga2010/DietaryGuidelines2010.pdf [8].

The first edition of the Dietary Guidelines for Americans was released in 1980 and it is revised (if necessary) and published every 5 years in a joint effort between the U.S. Department of Health and Human Services (HHS) and USDA. [9] The Guidelines were preceded by the "Dietary Goals for Americans" released in early 1977 in response to the Government report that six out of ten leading causes of death have been linked to the diet. [10] Currently, 2010 Guidelines are in place and the 2015 edition is underway [11].

Food Guides are pictorial representations using different approaches to show which foods to emphasize and which to minimize. Their focus is also on preventing or reducing risks for chronic diseases, not necessarily on preventing nutrient deficiency. The first such guide, developed in 1946 was a wheel illustrating the "Basic 7" created by the U.S. Department of Agriculture which detailed grouped foods into 1) leafy green, yellow vegetables, 2) citrus fruit, tomatoes, raw cabbage, 3) potatoes and other vegetables and fruits, 4) milk, cheese, and ice cream, 5) meat, poultry fish, eggs, dried peas, and beans 6) bread, flour, cereals, whole-grain or enriched, and 7) butter and fortified margarine [12].

Many other food guides were released by the USDA up until 1992 when the classic Food Pyramid was created. It divided into six horizontal sections containing foods from each food group, with the food group providing the largest portion of calorie intake located on the bottom (e.g. grains, carbohydrates). This version of the Food Pyramid was updated in 2005 with colorful vertical wedges replacing the horizontal sections, with an added a depiction of physical activity, and renamed MyPyramid [13]. Subsequently, several versions of MyPyramid were issued, with respect to the particular food preferences of the elderly, of children and of various ethnic groups.

The high level of public confusion and evidence from new research leading to controversies with the pyramid-type recommendations eventually led to the development of MyPlate, in June 2011, as a more user-friendly and easier-to-visualize symbol [14]. My Plate is divided into four slightly different-sized quadrants, with fruits and vegetables taking up half the plate, and grain and protein sections in the other half. A glass of milk representing one dairy serving is provided on the side. This pictorial is accompanied by more specific dietary and exercise recommendations which highlight the nutrient needs for individuals for an entire day, as opposed to just one meal, found at www.choosemyplate.gov.

\section{Dietary Reference Intakes (DRI)}

DRIs evolved from the Recommended Dietary Allowances (RDA) in 1997. Historically, the primary goals of RDAs (as the goals of other recommendations) were to provide recommendations toward preventing nutrient deficiencies and subsequent deficiency diseases. The focus now is on "healthy" populations, setting parameters for consumption of macro- and micro-nutrients and energy to meet dietary requirements as well as to reduce risks for chronic diseases. Separate allowances are provided for different age groups and gender, and proper adjustments are made for pregnancy and lactation [15].

\section{Evolution of Recommended Dietary Intakes (RDA)}

The Food and Nutrition Board (FNB), a part of the National Academy of Sciences, was first established when the US entered World War II [16]. The FNB was charged with the mission to provide counsel to the Army about problems related to food intake and the overall nutritional status of the country. They recognized a need to create recommendations on nutrient requirements of the armed forces as well as the general US population [17]. In 1941 the first RDAs were published by the Food and Nutrition Board and included 6 pages. Since then, 9 successive editions were published (about every 5 years) until 1989 when (last) edition of RDAs, as they were, appeared. The original definition of RDA, which still holds is: "The levels of intake of essential nutrients, that, on the basis of scientific knowledge, are judged by the Food and Nutrition Board to be adequate to meet the known nutrient needs of practically all healthy persons" [17]. However, over time several problems associated with the RDAs became apparent as well as the need for some major changes and overhaul of the basic concepts [18].

During the nineties, sufficient evidence accumulated to warrant new recommendations for many nutrients. In addition, the recommendations needed to account how nutrients may or may not reduce the risk of chronic disease, not just those necessary to prevent nutritional deficiencies. The upper limits of nutrient intake needed to be defined more specifically. The bioavailability and interaction among nutrients needed to be accounted for, as well as the role of other food components (not classically considered nutrients and alcohol) and their synergistic or inhibitory effects. Therefore, restructuring the existing RDA format was attempted and resulted in the creation of the DRIs. The DRIs encompass a framework with a set of four nutrient-based reference values intended primarily for use in assessing and planning diets for healthy people in the USA and Canada [18]. All information about DRIs can be found at: http:// fnic.nal.usda.gov/dietary-guidance/dietary-reference-intakes [15].

\section{Briefly, the DRI components include:}

1) Estimated Average Requirements (EAR) represent an intake estimated to meet the requirement of $\sim 50 \%$ of people in a specific age, life stage, and gender group (and falls below the requirements for the other half). EARs are established based on experimental data and are used to calculate the RDAs.

2) Recommended Dietary Allowances (RDA) represent an intake estimated to meet the requirement of $\sim 98 \%$ of healthy people in a specific age, life stage, and gender group. They are established by using the EAR and adding 2 standard deviations (SD) of the EAR. If SD is not available, the factor of 1.2 or 1.3 is used to multiply the EAR in order to derive the RDA of that particular nutrient.

3) Adequate Intakes (AI) are used when there is no sufficient data to establish an EAR and subsequent RDA. They exceed RDA and therefore should cover most individuals in the particular population group. Although there is less certainty about AIs, as they are based on scientific judgment, they are used in the same manner as RDAs for planning and addressing the needs of a group or population.

4) Tolerable Upper Intake Levels (UL) are established for some of the nutrients and they are the highest average daily nutrient intake levels not producing adverse health effects. As intake level above the UL increases, so does the risk of an adverse event.

The Institute of Medicine (of the USA National Academies of Sciences) and its Food and Nutrition Board regularly print series of 
Page 3 of 3

updated DRI reports to reflect the most current science surrounding the relationship between nutrients and health and disease. Thus, the nutrition professionals (and the lay public) have the opportunity to take advantage of reference values for nutrients and plan for the diets to decrease both traditional nutritional deficiency diseases and the risks for chronic diseases, as well as for overall improvement of health status [19].

\section{References}

1. Great Britain (1844) An Act to amend and consolidate the Laws relating to Merchant Seamen; and for keeping a Register of Seamen. In: British General Public Statutes 7th \& 8th Victoria Cap. CXIIEyre G W, Spottiswoode W (ed.) Printers to the Queen, Canada.

2. Kennedy BP (1916) The Seamen's Act. Annals of the American Academy of Political and Social Science 63:232-243.

3. United States (1890) Office of Experiment Stations. Experiment Station Record, Washington DC 1: 99-100.

4. Agricola: Accessed August 2014.

5. Atwater WO, Woods CD (1896) The chemical composition of American food materials. USDA Bulletin 28: 1-41.

6. Atwater WO, Milner RD (1899) Studies of dietaries of college students and of members of families of professional men. Storrs Station Report.

7. Dupont JL, Harper AE (2002) Hazel Katherine Steibeling (1896-1989). Nutr Rev 60:342-348.

8. Dietary Guidelines for Americans.
9. History of the Dietary Guidelines for Americans. Policy Document.

10. Staff of the Select Committee on Nutrition and Human Needs United States Senate (1977) Dietary Goals for the United States. 95th Congress. 1st Session. U.S. Government Printing Office, Washington, D.C.

11. U.S. Department of Agriculture and U.S. Department of Health and Human Services (2010) Dietary Guidelines for Americans. U.S. Government Printing Office, Washington, D.C.

12. United States Department of Agriculture. National Archives and Records Administration.

13. MyPyramid Accessed August 2014.

14. MyPlate. Accessed August 2014.

15. Dietary Reference Intakes.

16. Institute of Medicine (US) Food and Nutrition Board (1994) How Should the Recommended Dietary Allowances Be Revised? 2, Concepts Underlying the Recommended Dietary Allowances. National Academies Press, Washington, DC.

17. National Research Council (1989) Recommended Dietary Allowances (10thedn). The National Academies Press, Washington, D.C.

18. National Research Council (2000) Dietary Reference Intakes: Applications in Dietary Assessment. National Academy Press, Washington, D.C.

19. Taylor CL (2008) Framework for DRI Development: Components "Known" and Components "To Be Explored". Background Paper. Collaboration with U.S. Federal DRI Steering Committee. Scholar, Food and Nutrition Board, Institute of Medicine National Academies, Washington, D.C. 